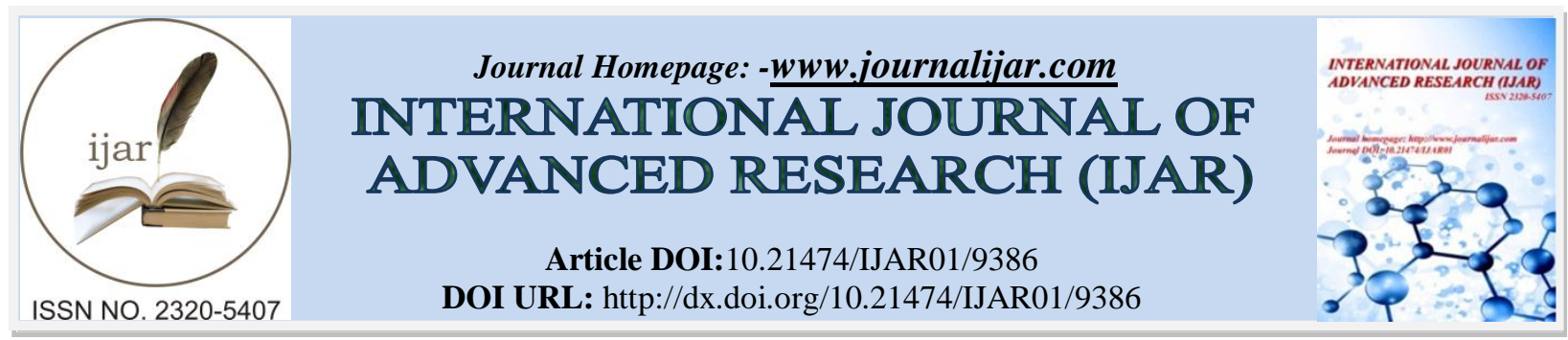

RESEARCH ARTICLE

\title{
STEREOMICROSCOPIC COMPARATIVE ANALYSIS OF MICROLEAKAGE IN ROOT CANAL OBTURATED WITH C-POINTS, GUTTAFLOW, AND GUTTA PERCHA-AN IN VITRO STUDY.
}

\section{Dr. Ansita Gupta ${ }^{1}$, Dr. Lalit c. Boruah ${ }^{2}$ and Dr. B. rajkumar ${ }^{3}$.}

1. Student,department of conservative and endodontics,(14 keshav nagar-3,,Near Geetanjali Colony,Chotisadri Road, Nimbahera-312601 Rajasthan)

2. Professor, (department of conservative and endodontics), Babu Banarasi Das College of dental sciences Lucknow.

3. Professor and head (department of conservative and endodontics), Babu Banarasi Das College of dental sciences Lucknow.

\section{Manuscript Info}

Manuscript History

Received: 15 May 2019

Final Accepted: 17 June 2019

Published: July 2019

\section{Abstract}

Aim: The aim of this study is to assess microleakage of three root canal filling materials using a dye penetration method under stereomicroscope.

Background: C-Pointis a self-sealing obturation technology that relies on naturally occurring dentinal moisture to radially expand and adapt to irregular canal spaces.

Methodology: A total of 30 extracted human single-rooted teeth were selected; the working length was determined by subtracting $1 \mathrm{~mm}$ from the total length of the root. The chemo-mechanical preparation were completed up to size 30/0.06\% taper using rotary system (Protaper next). Each canal were irrigated with $1 \%$ Sodium Hypochlorite with a 27 gauge needle and 17\% EDTA. The prepared teeth were divided into 3 groups of 10 teeth each for obturation. Group $1=$ Teeth obturated by gutta percha using ah plus sealer, group $2=$ Teeth obturated by Guttaflow system, group $3=$ Teeth obturated by c-point with bioceramic sealer. The teeth were subsequently sealed and stored in methylene blue dye solution for $48 \mathrm{hrs}$. They were then sectioned to evaluate the linear apical leakage dye penetration using a stereomicroscope.

\section{Introduction:-}

Complete obturation with three dimensional fluid tight seal of the root canal system is a critical step in successful root canal therapy; it should provide a fluid tight seal to inhibit penetration of bacteria and their byproducts into the cleaned and disinfected canals. Thus various materials and techniques for obturation have been developed from time to time.

The primary objectives of endodontics are total debridement of the pulpal space, development of a fluid-tight seal at the apical foramen and total obturation of the root canal system. ${ }^{2}$ 
According to Ingle the most common causes of endodontic failure is incomplete obturation, 59\% of endodontic failure were due to leakage in the root canal seal. ${ }^{2}$ Microleakage between root canal filling and root canal walls may adversely affect the outcome of root canal treatment. Therefore, complete obturation of the root canal system with an inert filling material and creation of an apical seal have been proposed as goals for successful endodontic treatment. $^{3}$

The three main objectives of obturation is to remove all the bacteria remaining in the root canal system, to stop the influx of periapical tissue derived fluid from re-entering the root canal and to prevent coronal leakage of bacteria. ${ }^{4}$ In the past root canal filling materials and techniques have been developed in a hope to achieve total root canal obturation. ${ }^{5}$ The root canals have been reported to be filled with amalgam, balsam, bamboo, cement, copper, goldfoil, iron, lead, oxy-chloride of zinc, paraffin paste, plaster of Paris, resin, rubber, silverpoints, tin foil and a lot more materials. ${ }^{6}$

Gutta-percha was first introduced by HILL (1847) in restorative dentistry and by G.A. Bowman (1867) in endodontics. Gutta-percha is a dried coagulated extract of plant of balaquium, Blanco genus of sapotaceae family. ${ }^{5}$ Gutta percha is the most commonly used obturation material in contemporary endodontic practice. It is known for its excellent properties that is-Chemical stability; biocompatibility ${ }^{7,}$ inert nature; ability to adapt to the canal walls, low tissue irritation, its permanency (Wein 1962, Grossman 1983) and property of flow when gutta-percha is heated. Chemically pure Gutta-percha exists in two distinctly different crystalline forms $(\alpha$ and $\beta)$,

That can be interconvertible, so taking advantage of the phase transformation of the gutta-percha various obturation techniques have been developed from time to time. ${ }^{8}$

Numerous methods have been proposed to fill the root canal. Current techniques are still based on gutta-percha and sealer to achieve this goal; despite the advent of numerous techniques and rotary instrumentation systems the lateral compaction technique remains as a widely used option because of its simplicity and low cost. ${ }^{9}$

\section{Recently newer materials have been introduced for better obturation like Guttaflow and C-point.}

Guttaflow (ColtenlwaledentAltstätten, Switzerland) is a thixotropic root canal filling material which combines the sealer polydimethyl siloxane with fine gutta percha powder. it is the first sealer gutta percha combination which is flowable at room temperature. ${ }^{8}$ The finely ground gutta-percha powder and the silicone-based matrix are distributed homogeneously after mixing. Gutta-flow has very promising properties because of its insolubility, biocompatibility, post-setting expansion, great fluidity, and for providing a thin film of sealer. Gutta-Flow has nano-silver in its composition. Nano-silver is metallic silver which is distributed uniformly on the surface of the filling. The chemical type and concentration of the nano-silver do not cause corrosion or colour changes in the Guttaflow. There is sufficient nano-silver in the material to prevent further spread of bacteria and is highly biocompatible. ${ }^{10}$

The most recent advancement in the endodontic obturation materials utilizes a hydrophilic polymer in the root canal, the C-point system (Endo technologies, Shrewsbury, USA). Which consist of a prefabricated obturation points containing a polyamide core with an outer bonded hydrophilic polymer coating and an accompanying bioceramic sealer which is biocompatible and hydrophilic, composed of calcium silicate, monobasic calcium phosphate, zirconium oxide, proprietary fillers, and thickening agents. The deformable C-point is available in different tip sizes and tapers and is designed to expand laterally without expanding axially, by absorbing residual water from naturallyoccurring intraradicular moisture. ${ }^{7}$ Micro leakage is a crucial parameter in obturation. Several methods have been described to evaluate the microleakage of obturated root canals like stereomicroscope, sccaning electron microscope, cone focal microscope, Spectrophotometer (Light transmission), CBCT, In this in-vitro study stereomicroscope is used to access microleakage because it provides large working distance at low magnification in examining large solid objects and is associated with an image analysis which can be done by visual interpretation of the parameters. No one material up/till able to fulfill this drawback. Many attempts have been made to resolve this problem by variation and modification in obturation technique as well as material including Gutta percha, Guttaflow, and C-point.

\section{Aim:-}

The aim of this study is to assess microleakage of three root canal filling materials using a dye penetration method under stereomicroscope. 


\section{Objectives:-}

The objectives of this study are =

1. To evaluate the micro leakage of Lateral compaction.

2. To evaluate the micro leakage C-point.

3. To compare the microleakage of conventional gutta percha, Guttaflow and c-point using stereomicroscope.

\section{Material and method:-}

This study is carried out in the department of conservative dentistry and endodontic Babu Banarasi Das college of dental sciences Lucknow and the facility of Stereomicroscope was availd from Birbal Sahani institute; palaeobotany, Lucknow.

\section{Eligibility Criteria:}

1. Inclusion criteria- 30 intact human single rooted premolars extracted for orthodontic reasons with closed apices were included for the study.

2. Exclusion Criteria-Premolars having dental caries, cervical abrasion, calcifications, previous restoration or endodontic manipulation, fractures or cracks, internal or external resorption and dilacerations will be excluded.

\section{Preparation of the samples-}

The extracted teeth were cleaned using ultrasonic scaler and Sectioned at cement-enamel junction using water cooled diamond disc, then kept in sterile physiological saline solution at room temperature.The working length was determined by subtracting $1 \mathrm{~mm}$ from the total length of the root. The chemo-mechanical preparation was completed up to size 30/0.06\% taper using rotary system (Protaper). Each canal was irrigated with $2 \%$ Sodium Hypochlorite with a 27 gauge needle and 17\% EDTA. The prepared teeth were divided into 3 groups of 10 teeth each.

1. GROUP $1=$ TEETH OBTURATED BY GUTTA PERCHA USING AH PLUS SEALER

2. GROUP $2=$ TEETH OBTURATED BY GUTTAFLOW SYSTEM with master cone

3. GROUP 3=TEETH OBTURATED BY C-POINT with bio-ceramic sealer

\section{Armamentarium used in study-}

1. Access cavity kit (Dentsply co. USA)

2. High speed airoter hand-piece (NSK)

3. k-File no.10 (Dentsply)

4. X-smart Endomotor (Dentsply)

5. Endoblock (Dentsply)

6. Glyde (Dentsply)

7. $2 \%$ Sodium Hypochloride solution (Septodont)

8. $17 \%$ EDTA Solution (Rankem)

9. Normal saline

10. Micromotor Straight Handpiece (Unicorn)

11. Fine diamond disc (Dentsply)

12. No. 6 round diamond point (S.S.White)

13. C Points obturation system 30 sizel0.06\% taper (Endo technologies, Shrewsbury, USA)

14. Bioceramic root canal sealer (Endosequence; BRASSELER USA)

15. Guttaflow with master cone (coltenlwaledentAltstätten, Switzerland)

16. Gutta percha cone 30 SIZE/0.06\% taper (Meta biomed) and $2 \%$ taper

17. A H plus sealer (Dentsply)

18. Methylene blue dye (S.D.Fine-Chem Limited Mumbai 400 025)

19. Stereomicroscope (Lieca)

\section{Methodology:-}

The obturation of each group was done following manufacturer's instructions. The obturation material was removed in all groups up to $2 \mathrm{~mm}$ apical to the orifice and cervically sealed with restorative Glass ionomer cement. The samples were then placed in an incubator for 48 hours at $37^{\circ} \mathrm{C}$ for $100 \%$ humidity to allow the sealer to set.

1. Following obturation, the root surfaces of all samples were coated with two coats of nail varnishes up to the apical $2 \mathrm{~mm}$. The teeth were then immersed into methylene blue dye. The samples were then left in incubator 
undisturbed for $72 \mathrm{hrs}$ at $37^{\circ} \mathrm{C}$, after removing from dye solution; the specimens were washed with water and dried.

2. The teeth were then sectioned vertically with diamond disc along the long axis in the bucco-lingual direction through the centre of the root. The samples were then observed under stereomicroscope. The dye leakage was measured from the apical constriction to the longest point of dye penetration along the canal walls and obturation material itself using Stereomicroscope. The obtained results were submitted for statistical analysis.

\section{The three study groups are as follow-}

\section{Group 1-Teeth Obturated By Gutta Percha Using Ah plus Sealer}

After cleaning and shaping the canal was dried with paper points. A standardized Gutta percha master point was fitted in the root canal upto the working length and was checked for tug-back.AH-Plus sealer (Dentsply), was mixed according to the manufacture's instruction and was applied to the canal wall using a file size no 20 with a counter clockwise rotation. The apical part of the master gutta-percha point was then coated with the sealer and was introduced slowly into canal upto the working length. The lateral compaction was done using standardized finger spreader and gutta-percha points. The gutta-percha cones coated with sealer were laterally compacted; Excess guttapercha was removed with a heated instrument. Then coronal portion of the tooth is restored with glass inomer cement.

\section{Group 2-Teeth Obturated By Guttaflow with Master Cone.}

In this technique a capsule of Guttaflow (coltenlwaledentAltstätten, Switzerland) underwent trituration for 30s in a vibrator. Then Guttaflow was placed on a mixing pad for coating master-cones. The prefitted master-cone coated with additional Guttaflow was introduced into the canal up till working length. Backfilling of the Guttaflow sealer was perfomed by inserting the special tip between the master cone and canal walls. The master point was pulled coronally and pushed back apically with firm pressure applied for 8 seconds to avoid any entrapment of air bubbles. The butt end of the gutta percha point is then seared off with a red hot ball burnisher placed at the canal orifice. Then coronal portion of the tooth is restored with glass inomer cement.

\section{Group 3-Teeth Obturated By C-Point with Bio-Ceramic Sealer.}

In this group, teeth were obturated with C-Points obturation system (EndoTechnologies, Shrewsbury, USA), also known as Propoints which is a part of the Smartseal obturation system and is a novel single-cone hydrophilic system.In this system C-point that matches the size of the final file used to obturate the canal and that reach upto full working length, until a tug-back could be felt. Radiograph was taken to confirm the position of the c-point. Then the premixed bioceramic Sealer was placed. The sealer is introduced into the coronal 2/3 of the canal using the provided syringe tips followed by placement of the C-point into the canal to the working length using tweezers. A slow firm pressure was required to allow the point to evenly distribute the sealer down into the canal. Then C-point was trim at the level of the canal orifice using a high-speed hand piece, and a diamond bur. Then coronal portion of the tooth was restored with glass inomer cement.

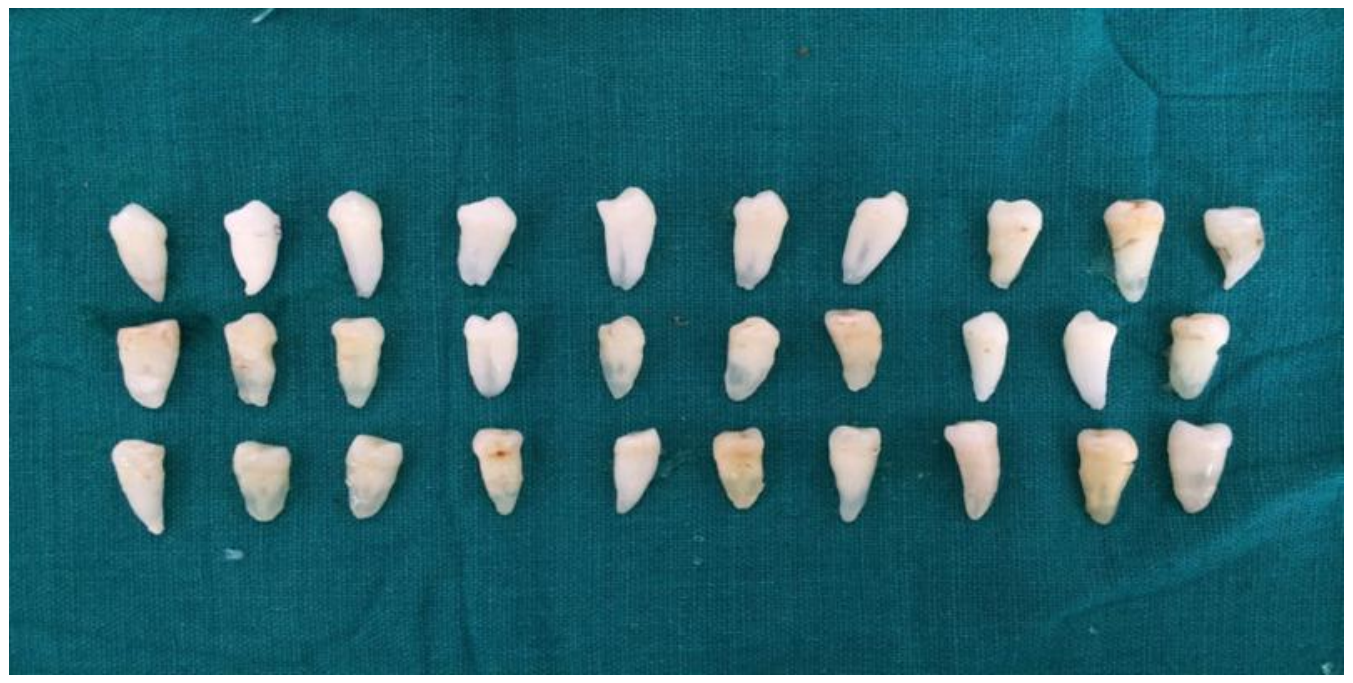

Figure 1:-Thirty human extracted mandibular first premolars 

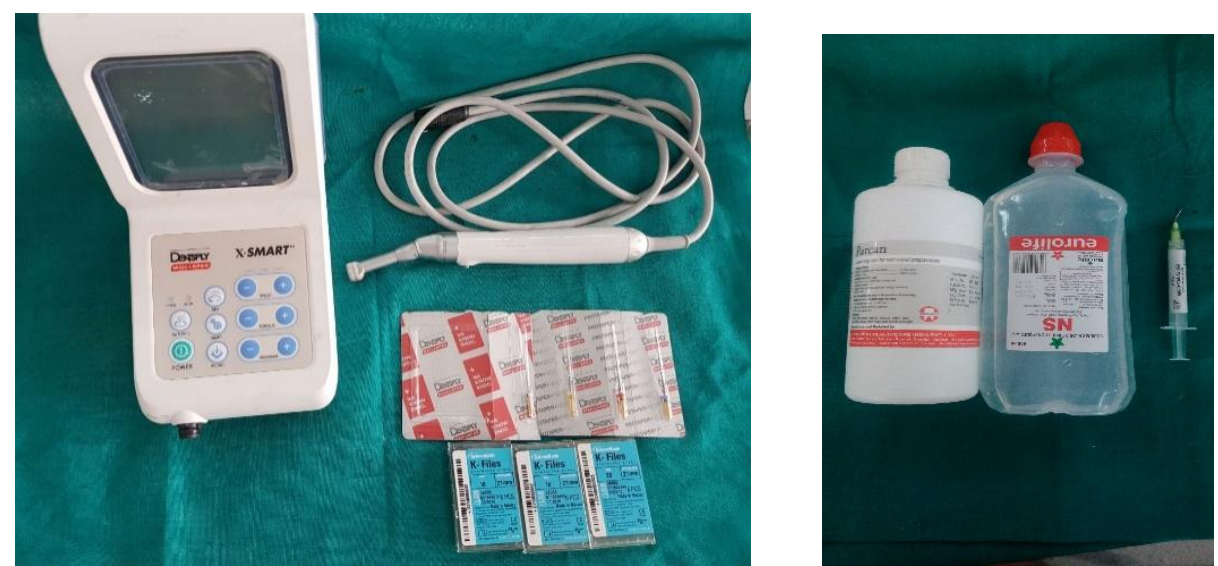

Figure 2:-Armamentarium used

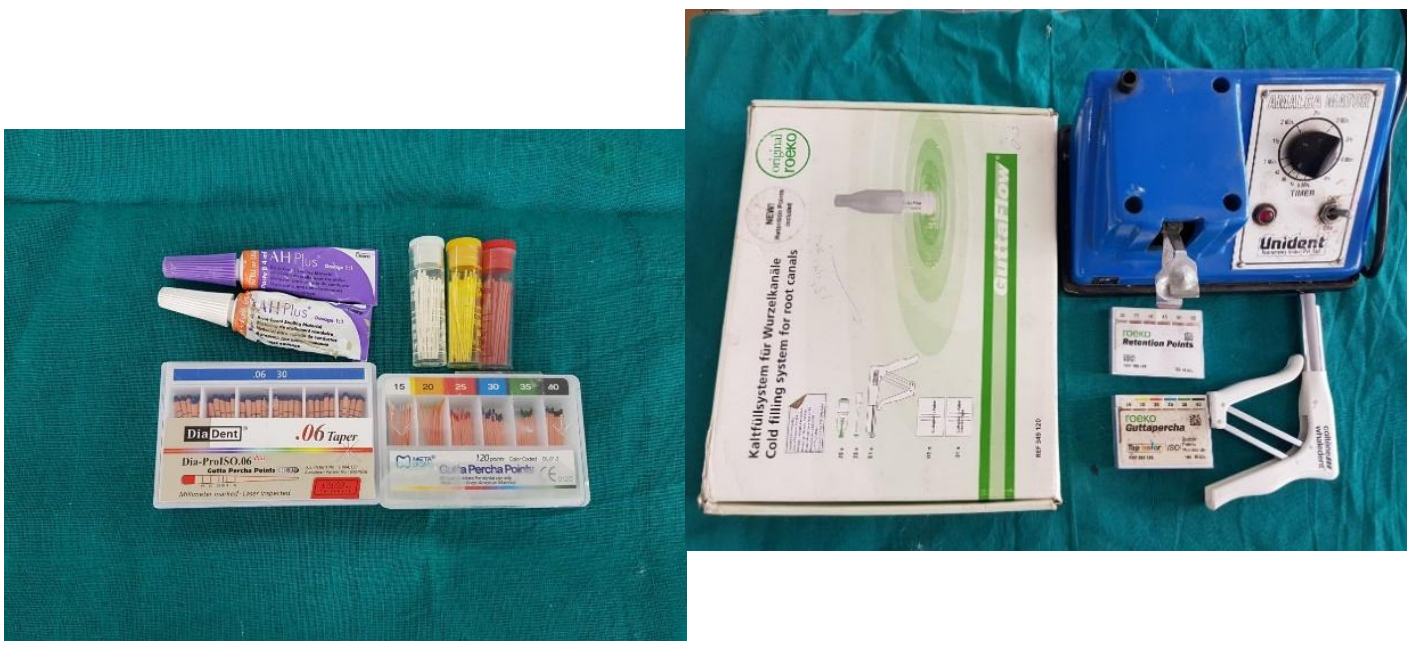

Figure 3:-Gutta percha and AH Plus sealer Figure 4:-Guttaflow system

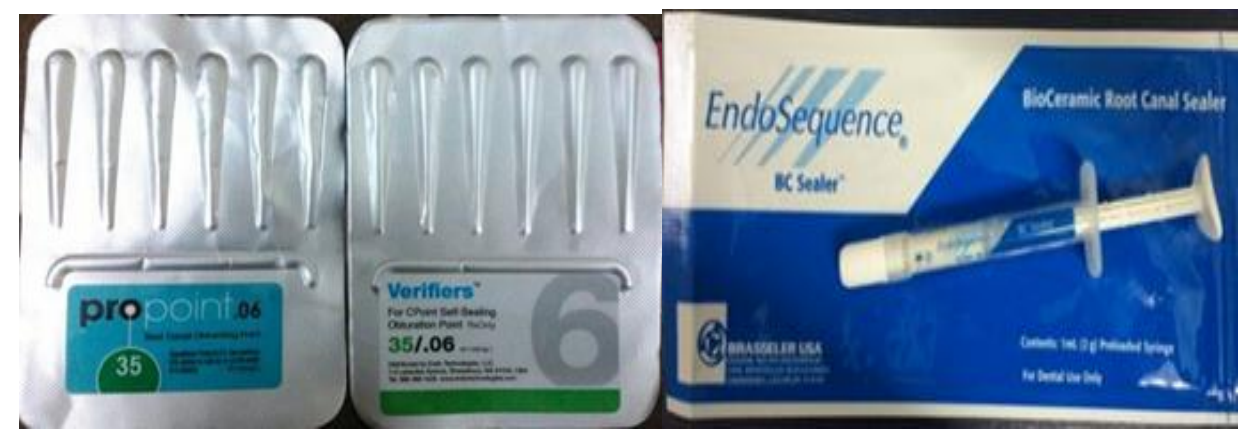

Figure 5:-C-Point obturation system 


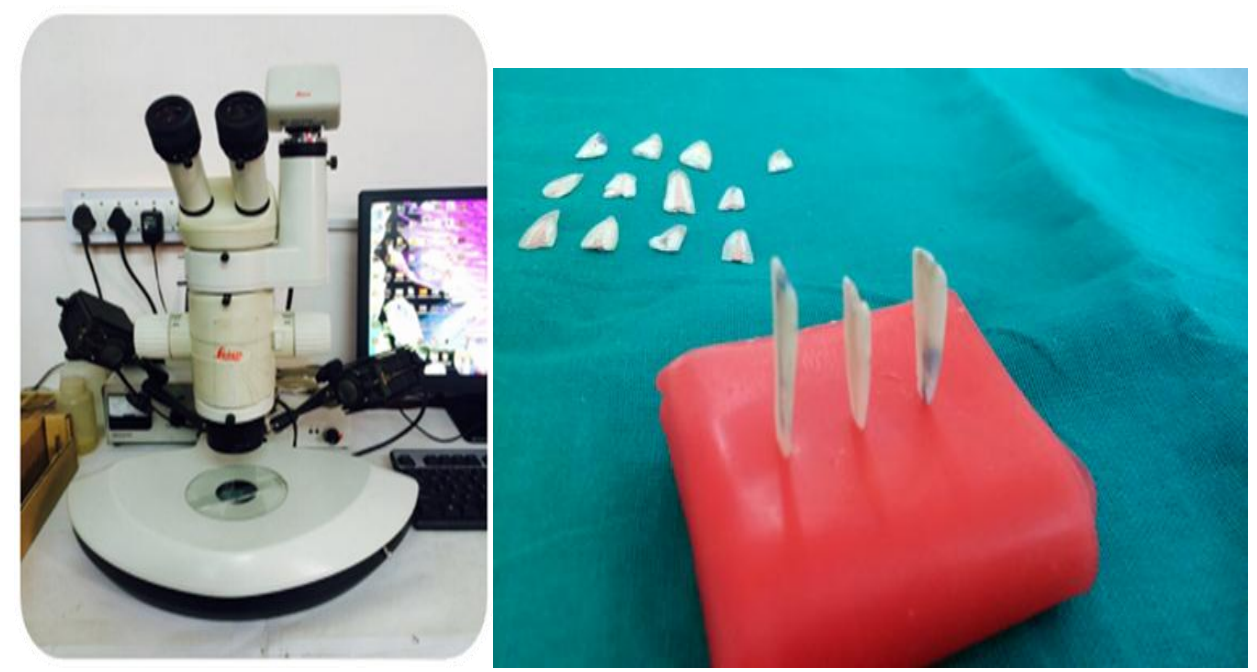

Figure 6:-Stereomicroscope and incubatorFigure 7:-sectioning

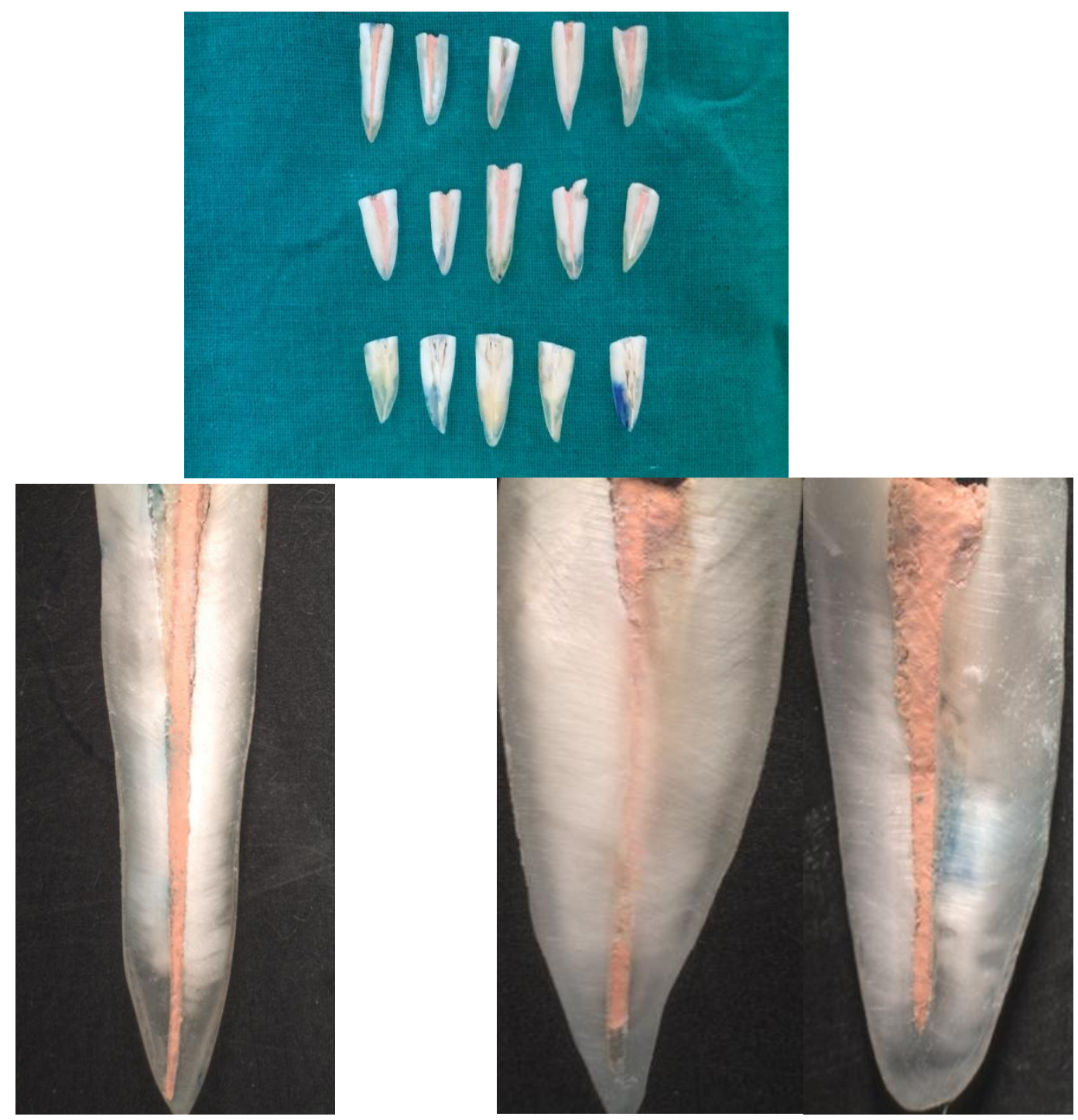

Figure 7:-Stereomicroscope image (guttaflow obturation technique) 


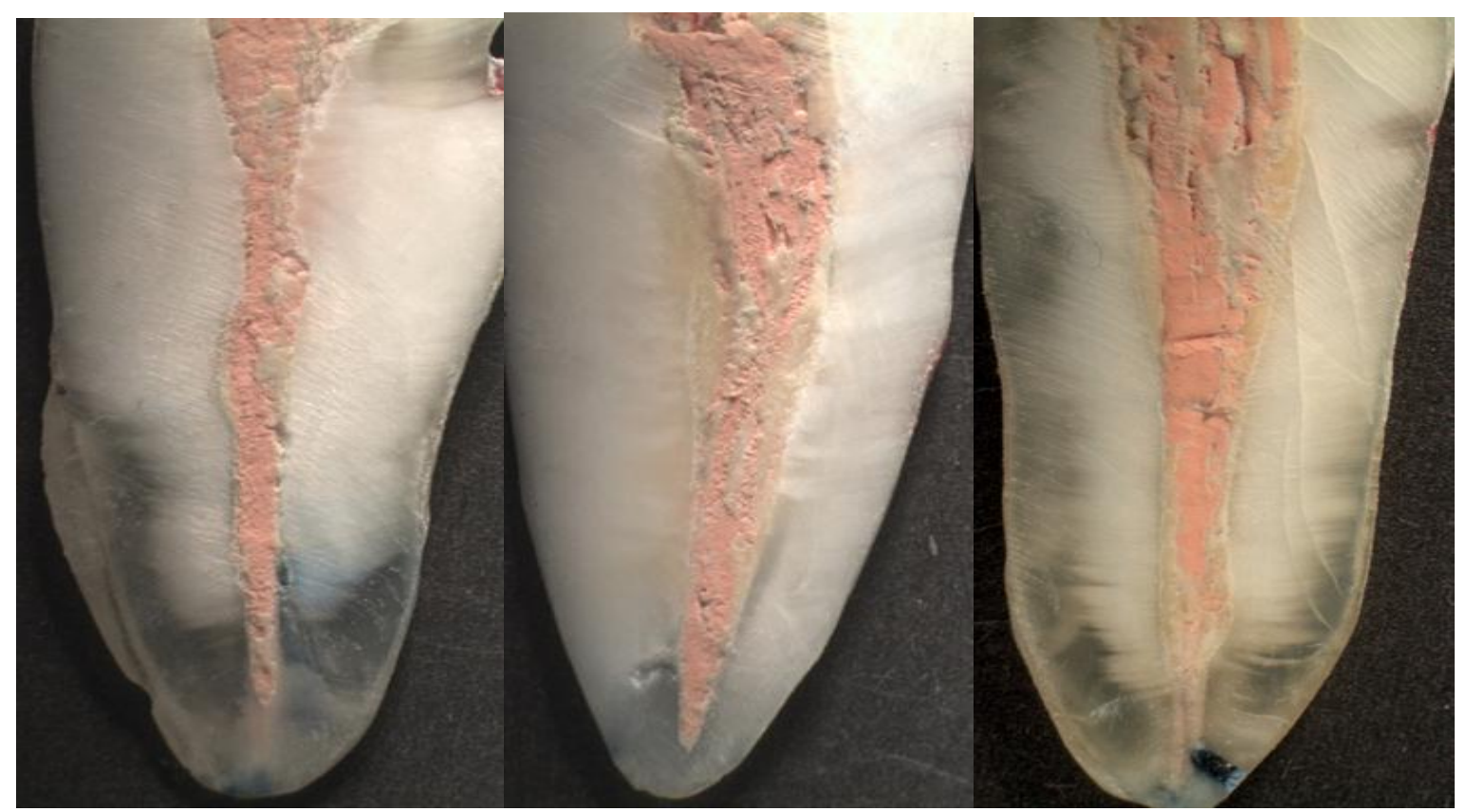

Figure 8:-Stereomicroscope image (lateral compaction technique)

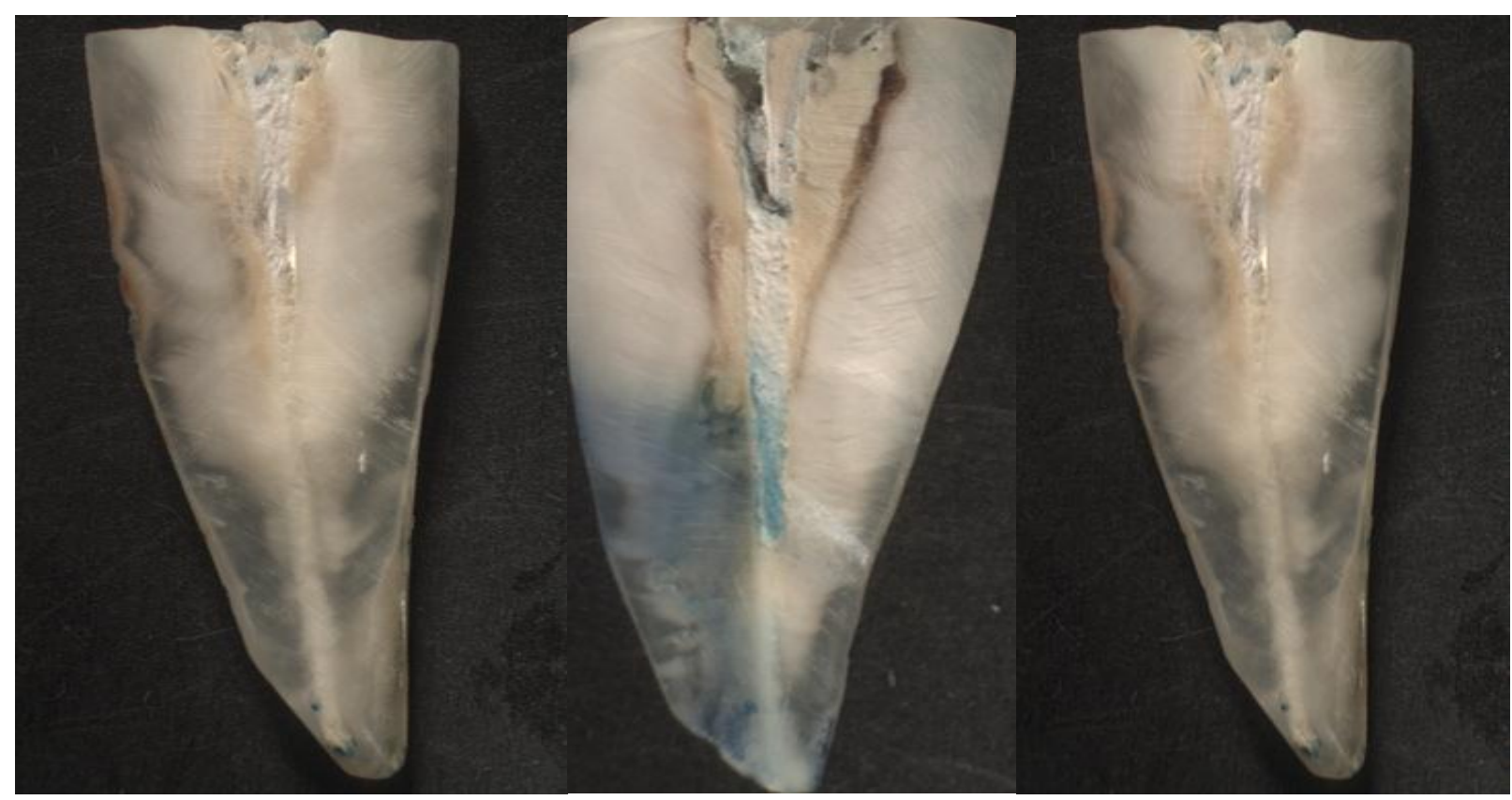

Figure 9:-Stereomicroscope image(C-Point obturation system)

\section{Results:-}

Statistical analysis:-

Data were summarized as Mean \pm SE (standard error of the mean). Groups were compared by oneway analysis of variance (ANOVA) and the significance of mean difference between the groups was done by Tukey's HSD (honestly significant difference) post hoc test after ascertaining normality by Shapiro-Wilk's test and homogeneity of variance by Levene's test. A two-tailed $(\alpha=2) \mathrm{p}$ value less than $0.05(\mathrm{p}<0.05)$ was considered statistically significant. Analysis was performed on SPSS (Windows version 17.0). 


\section{Results and Observations:-}

The present in vitro study evaluates the stereomicroscopic comparative analysis of microleakage in root canals obturated with lateral compaction (LC), Guttaflow (GF), and C-points (CP). The outcome measure of the study was microleakage measured in $\mathrm{mm}$. The objective of the study was to compare the microleakage among the groups.

\section{Sample and group}

In the present study, total 30 intact human single rooted premolars extracted for orthodontic reasons with closed apices were included.Randomise equally in three groups. The sample, material used and allocation of groups is summarized in Table 1 and also depicted in Fig. 1.

Table 1:-Distribution of samples, material used and allocation of groups

\begin{tabular}{|l|l|l|}
\hline Maternal used & Group name & $\begin{array}{l}\text { No of samples } \\
(\mathbf{n = 3 0})\end{array}$ \\
\hline $\begin{array}{c}\text { a) GUTTA PERCHA USING AH } \\
\text { PLUS SEALER }\end{array}$ & Group 1 & 10 \\
\hline $\begin{array}{c}\text { b) GUTTAFLOW SYSTEM with } \\
\text { master cone }\end{array}$ & Group 2 \\
\hline $\begin{array}{c}c \text { ) C-POINT with bio-ceramic } \\
\text { sealer }\end{array}$ & Group 3 & 10 \\
\hline
\end{tabular}

Table 2:-Observed microleakage length and width at interface of root canal filling $(\mathrm{mm})$ of three groups

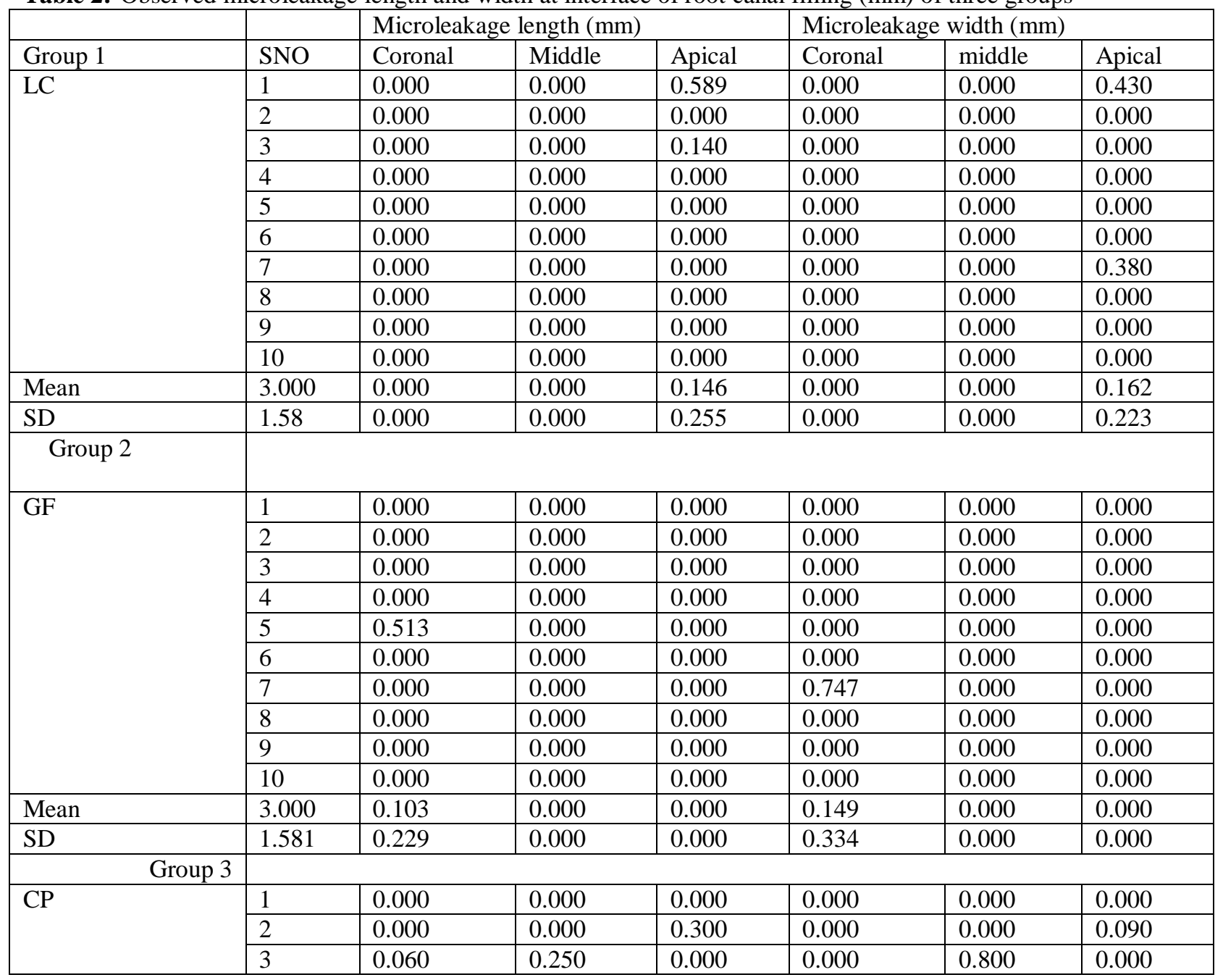




\begin{tabular}{|l|l|l|l|l|l|l|l|}
\hline \multirow{5}{*}{} & 4 & 0.000 & 0.000 & 0.000 & 0.000 & 0.000 & 1.650 \\
\cline { 2 - 8 } & 5 & 0.000 & 0.000 & 0.000 & 0.000 & 0.000 & 0.000 \\
\cline { 2 - 8 } & 6 & 0.000 & 0.000 & 0.280 & 0.000 & 0.000 & 0.000 \\
\cline { 2 - 8 } & 7 & 0.000 & 0.000 & 0.130 & 0.000 & 0.000 & 0.250 \\
\cline { 2 - 8 } & 8 & 0.000 & 0.000 & 0.120 & 0.000 & 0.000 & 0.000 \\
\cline { 2 - 8 } & 9 & 0.000 & 0.000 & 0.000 & 0.060 & 0.000 & 0.940 \\
\cline { 2 - 8 } & 10 & 0.000 & 0.000 & 0.000 & 0.000 & 0.000 & 0.000 \\
\hline Mean & 3.000 & 0.012 & 0.050 & 0.166 & 0.012 & 0.160 & 0.586 \\
\hline SD & 1.581 & 0.027 & 0.112 & 0.124 & 0.027 & 0.358 & 0.700 \\
\hline
\end{tabular}

Fig 1:-Mean microleakage width of three groups.

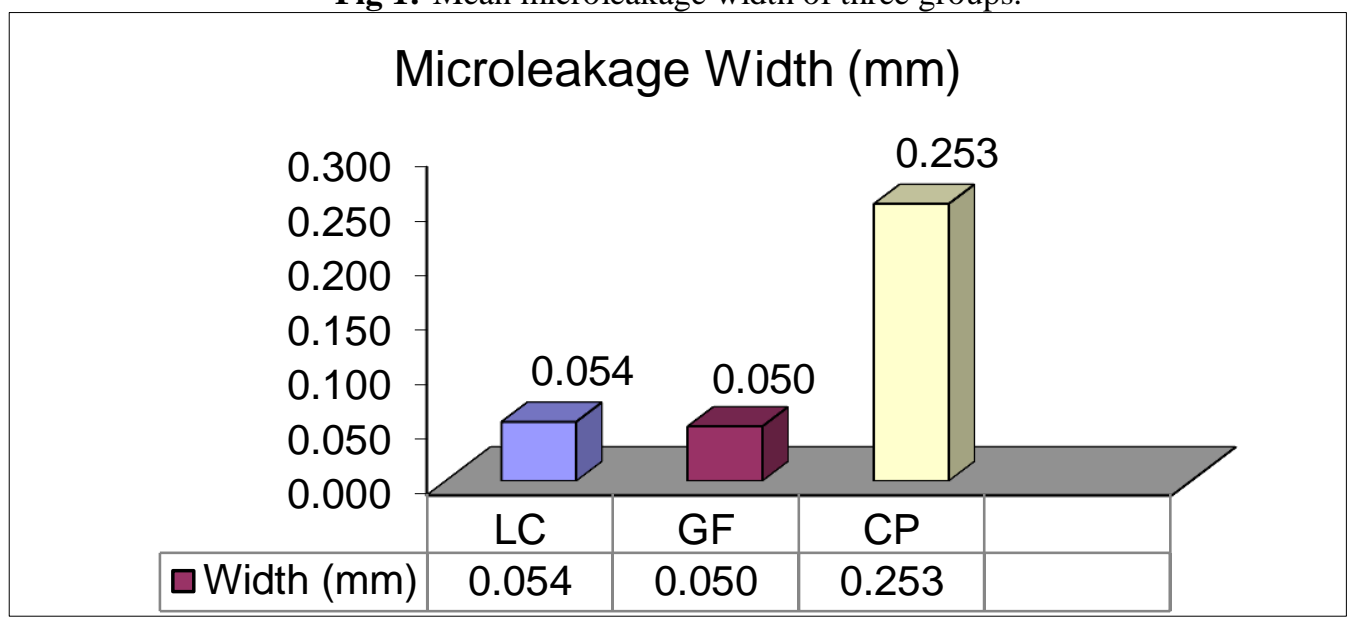

Table 3:-Microleakage (Mean $\pm \mathrm{SE}, \mathrm{n}=10$ ) of three groups

\begin{tabular}{|c|c|c|c|c|}
\hline LC & GF & CP & F VALUE & P VALUE \\
\hline $0.054 \pm 0.033$ & $0.050 \pm 0.050$ & $0.253 \pm 0.133$ & 2.02 & 0.151 \\
\hline
\end{tabular}

Table 4:-Comparison (p value) of mean difference in microleakage between the groups by Tukey test

\begin{tabular}{|c|c|c|c|}
\hline Mean difference & $\boldsymbol{P}$ value & $\boldsymbol{q}$ value & 95\% CI \\
\hline 0.004 & 1.000 & 0.06 & -0.30 to 0.30 \\
\hline 0.199 & 0.267 & 2.69 & -0.50 to 0.10 \\
\hline 0.203 & 0.251 & 2.74 & -0.50 to 0.10 \\
\hline
\end{tabular}

Fig 2:-Mean microleakage length of three groups.

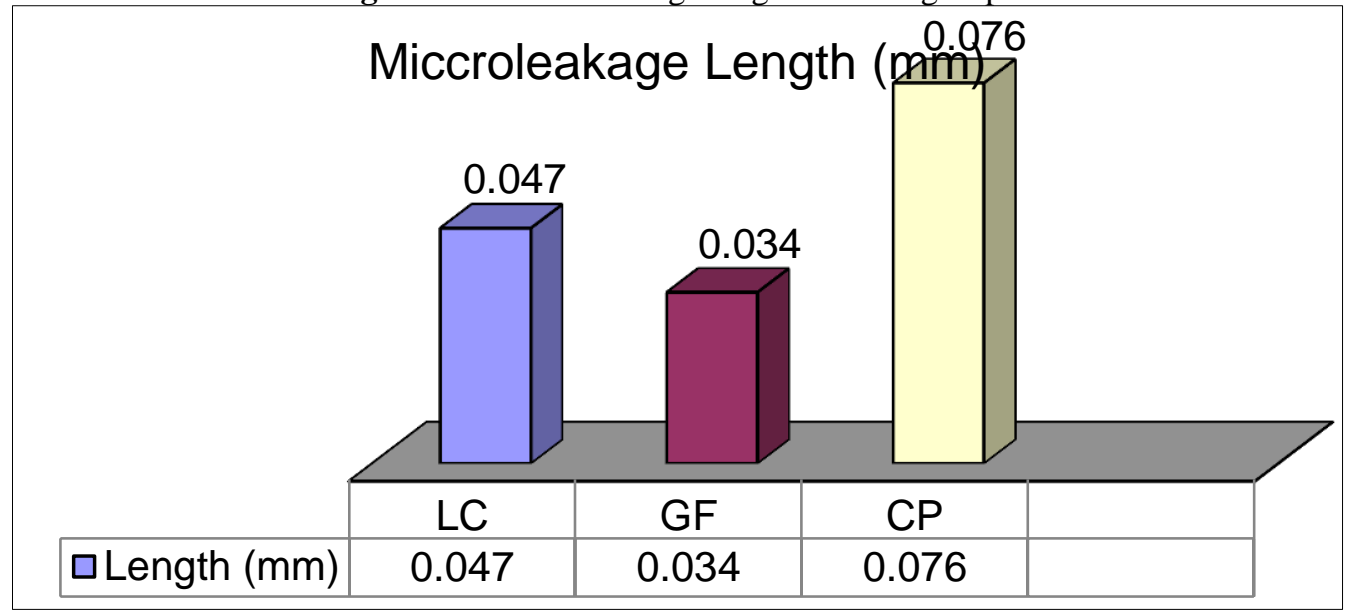




\section{Microleakage at interface-}

The microleakage at interface of the root canal filling and the dentinal wall (mm) of three groups (LC, GF, and CP) is summarized in Table 1 and also depicted in Fig. 1. Table 1 and Fig. 1 both showed that the mean microleakage of $\mathrm{CP}$ was highest in compare to LC, and GF and the least in GF (GF $<\mathrm{LC}<\mathrm{CP})$.

Comparing the mean microleakage of three groups, ANOVA showed similar microleakage among the groups $(\mathrm{F}=2.02, \mathrm{p}=0.151)$ (Table 1). Further, comparing the mean microleakage between the groups, Tukey test also showed significantly similar ( $>0.05$ ) microleakage among the groups 1 and 2 i.e. did not differ significantly (Table 2).

\section{Discussion:-}

This in-vitro study "Stereomicroscopic comparative analysis of microleakage in root canal obturated with C-points, Guttaflow, and Gutta percha" using Methylene Blue dye ((S.D. Fine-Chem Limited Mumbai 400 025)) was undertaken in the department of conservative dentistry and endodontic, Babu Banarasi Das College of Dental sciences. Stereomicroscopic examination was done in Birbal Sahani institute of paleobotany Lucknow.

The present study was done in-vitro as the clinical functions and characteristics are difficult to evaluate under invivo condition. The in-vitro tests give possibility to evaluate mechanical properties of restored teeth, and are considered as a predictor of the possible clinical performance of a material. The main aim of this study to evaluate the distribution of sealer around the root canal walls was possible by in-vitro study only.

For many years' endodontics has been the "Cinderella of dentistry". Countless teeth have been extracted because of an exposed or pain full tooth which was considered untreatable earlier.However, approach of the people towards dentistry as a whole and endodontic therapy in particular is undergoing a dramatic change. ${ }^{11}$

Success of non-surgical endodontics is well predicted and can be attributed to-

1. The meticulous cleaning and shaping of the root canal system.

2. It's three dimensional fluid tight obturation.

3. A well-fitting leakage free coronal restoration

A three dimensional obturation is critical for endodontic success. Micro leakage remains to be the most crucial cause of endodontic failure. Micro leakage is defined as the "passage of bacteria, fluids, and chemical substances between the root structure and filling material of any type. This occurs because of microscopic gaps at the interface of the filling material and the tooth. The objectives of obturation are-to achieve three dimensional (apical,coronal and lateral) fluid tight seal, to prevent percolation and microleakage of periapical exudates into the root canal space, to prevent re-infection, to create a favorable biological environment for tissue healing to take place. ${ }^{12}$

Incomplete root canal obturation has generally been considered as one of the principle cause of endodontic failure. In the past various materials and techniques have been tried to obtain a hermatic seal. The sealing ability and adaptability of various root canal filling materials were studied over years and it was found that none of the available material satisfactorily provide a hermetic seal. Thus because of the above reason currently used techniques utilize several materials for obturation. Numerous techniques have been developed to improve adaptation of the sealer to the root canal walls and to reduce its film thickness to minimum. ${ }^{13}$

Many attempts have been made to resolve this problem by variation and modification in obturation technique as well as material including Gutta percha, Guttaflow, and C-point.

Maeshal and Massler showed by way of isotopes that in a root canal procedure, Gutta-percha gives the best apical seal among the commonly used root canal filling techniques. ${ }^{14}$ Gutta-percha is the most universally used solid core root canal filling material to date. Chemically pure gutta-percha exists in two distinctly different reversible crystalline form (alpha and beta). ${ }^{15}$

In this study; 30 freshly extracted single rooted pre molar teeth extracted for orthodontic reasons were used for the study. The teeth were observed under magnifying loop and checked for the absence of immature root apices, cracks, root caries, fracture and resorption defects. After extraction, the teeth were placed in sterile physiological saline 
solution at room temperature, cleaned ultrasonically and sectioned at cement-enamel junction using water cooled diamond disc.

Instrumentation was performed by a crown down technique using protaper next Ni-Ti rotary instrument system.

The canal was irrigated between each instrumentation with $2 \% \mathrm{NaOCl}$ for 1 minute and then final flush of $17 \%$ EDTA ( $\mathrm{pH}$ 7.7) was done for 3 minute. Finally, the canals were washed with normal saline for removal of smear layer. GU et al. ${ }^{16}$ (2009), Wu et al. ${ }^{17}(2009)$ and Cecchin et al. ${ }^{18}$ (2010) concluded that the smear layer should be removed in order to allow for better penetration of the sealer into dentinal tubules.

AH Plus was chosen as an endodontic sealer in Group (I), and Endosequence bioceramic sealer was chosen as an endodontic sealer in Group (III).

AH Plus is an epoxy-amine resin based sealer and had improved properties including color and shade stability, good esthetic demands, easy to mix, adapt closely to the wall of the prepared root canal, provide minimal shrinkage upon setting and possesses outstanding long term dimensional stability, shorter setting time and more radio opacity as proved by S. Khedmat et al. ${ }^{19}$

AH Plus showed greater adhesion to root dentin than epiphany or any other root canal sealer. ${ }^{20}$ This is likely due to the fact that, as an epoxy resin based sealer,AH Plus had better penetration in the micro irregularities and dentinal tubules, which increase the mechanical inter locking between sealer and root dentin after the expansion of guttapercha. This fact allied to the cohesion among sealer molecules, increase the resistance to removal and displacement from dentine, which can be translated as greater adhesion. ${ }^{20} \mathrm{AH}-\mathrm{Plus}$ is reported to expand slightly during setting resulting in lower leakage.

Bioceramic sealer (Endosequence; BRASSELER USA) is a recently introduced Calcium Silicate based BC sealer, described by its manufacturer as an insoluble, radiopaque, aluminum-free material that requires the presence of water to set and harden. ${ }^{21,22}$

BC sealer being biocompatible and hydrophilic in nature it expands on setting forming a 'self seal', this expansion can reach upto $0.2 \%$ on completion of setting reaction. ${ }^{23}$ This expansion, chemical and micromechanical bonding all in total increase the bonding of the sealer to root canal walls. Adding to this, high pH (12.8) during the initial 24 hours of the setting process makes this sealer strongly antibacterial. ${ }^{21}$

There are two major advantages associated with the use of bioceramic materials as root canal sealers. Firstly, their biocompatibility prevents rejection by the surrounding tissues. Secondly, bioceramic materials contain calcium phosphate which enhances the setting properties of bioceramic and results in a chemical composition and crystalline structure similar to tooth and bone apatite materials, thereby improving sealer-to-root dentin bonding. However, one major disadvantage of these materials is in the difficulty in removing them from the root canal once they are set for later retreatment or post-space preparation. ${ }^{13}$

After sealer placement, the canals were obturated according to manufacturer's instructions. After the completion of obturation. The obturation material was removed in all groups up to $2 \mathrm{~mm}$ apical to the orifice and cervically and sealed with restorative Glass ionomer cement. The samples were then placed in an incubator for 48 hours at $37^{\circ} \mathrm{C}$ $100 \%$ humidity to allow the sealer to set.

After that the root surfaces of all samples were coated with two coats of nail varnishes up to the apical $2 \mathrm{~mm}$. The teeth were then immersed into methylene blue dye. The samples were then left in incubator undisturbed for $72 \mathrm{hrs}$ at $37^{0} \mathrm{C}$, after removing from dye solution; the specimens were washed with water and dried.

After drying all the specimens were longitudinally sectioned using a slow speed diamond disc. The quality of apical seal obtained by root canal obturation material can be assessed by various methods like bacterial penetration ${ }^{24}$ fluid transport $^{25}$, clarification ${ }^{26}$, penetration of radioisotopes ${ }^{27,28}$ electrochemical methods $^{29}$ and gas chromatography ${ }^{30}$. Dye penetration tests; however, seem to be the most widely used ${ }^{31,32,33}$ 
In this technique dye penetrationmethod was used because of its simplicity, ease to perform and it does not require sophisticated materials. Methylene blue dye was used as it is nontoxic (p H 3-4.5), its molecular size is similar to bacterial by-products $17 \mathrm{~A}^{0}$ such as butyric acid which can leak out of infected root canals to irritate periapical tissues. This dye was found to penetrate more up the canal than any other isotope traces. The teeth were placed vertically in the dye because in a study by Melvin et al, when teeth were placed horizontally in the dye, the air was trapped in the middle and did not allow the dye to penetrate fully.

The resulting samples were examined with a Wild Heerbrugg stereomicroscope under $6.5 \mathrm{X}$ magnification surface using Leica application software to determine the presence or absence of dye.

Stereomicroscopic examination was chosen for this study as this gives a three dimentional view of the surface to be examined, needs no pretreatment of the specimen (as in scanning electron microscopic examination) and is associated with an image analysis which can done by visual interpretation of parameters. ${ }^{34}$

The samples were then observed under stereomicroscope. The dye leakage was measured from the apical constriction to the longest point of dye penetration along the canal walls and obturation material itself. The obtained results were submitted for statistical analysis.

Lateral compaction of gutta-percha has remained the most widely used method of obturating root canals and is also often used as a control for evaluating sealing ability of new obturation techniques. Its advantages include predictability, relative ease of use, conservative preparation and controlled placement of materials. Disadvantages include time consuming, lack of homogeneity of gutta-percha mass, increased number of voids and sealer pools, and less adaptation to canal walls and irregularities ${ }^{8}$.

Gutta-flow contains gutta-percha particles in powder form, with particle size of less than $30 \mu \mathrm{m}$, and sealer (polydimethylsiloxane). The manufacturer claims a better seal and good adaptability because of increased flowability and the fact that this material expands slightly $(0.2 \%)$ on setting, enhancing its adaptation to root dentin walls. ${ }^{35}$

The lateral expansion of CPoints is claimed to occur non-uniformly, with the expandability depending on the extent to which the hydrophilic polymer is pre-stressed (i.e., contact with a canal wall will reduce the rate or extent of polymer expansion.

One of the prime reasons for increased microleakage in C Points would be due to limited moisture availability from intraradicular dentine for the expansion of the polymer. Furthermore, the canal was blot-dried with paper points before the sealer was applied.

\section{In this study, Gutta-flow was found superior to lateral compaction technique and C-point.}

The most likely explanation for low mean microleakage score in group 2 would be the setting expansion of Guttaflow by $0.2 \%$ as claimed by manufactures, and validated in studies. ${ }^{9}$ Post setting expansion are supposed to exhibit favorable sealing properties since expansion maximizes the movement of the material to fill voids and gaps between the main cone and the root canal walls and permits flow into canal irregularities to fill lateral canals and apical deltas. ${ }^{32}$

On evaluating the results, it was observed that C-point group shows highest Microleakage then lateral compaction and Gutta-flow.One of the prime reasons for increased microleakage in C Points would be due to limited moisture availability from intraradicular dentine for the expansion of the polymer.

Comparing the mean microleakage of three groups, ANOVA showed similar microleakage among the groups $(\mathrm{F}=2.02, \mathrm{p}=0.151)$ (Table 1). Further, comparing the mean microleakage between the groups, Tukey test also showed significantly similar ( $>0.05$ ) microleakage among the groups 1 and 2 i.e. did not differ significantly (Table 2). 


\section{Conclusion:-}

The present in-vitro study compared the microleakage in root canal obturated with C-points, Guttaflow, and Guttapercha with AH Plus sealer. With the results obtained after evaluation and comparison the following conclusion were drown from this study-

1. It was observed that C-point shows highest microleakage.

2. Though Guttaflow and Gutta percha with AH plus sealer shows no statically significant difference in microleakage, the better results were shown by Guttaflow.

\section{Bibliography:-}

1. Mobarak A, Moussa S, Zaazou A, Abdelfattah H. Comparison of bacterial coronal leakage between different obturation materials (an in vitro study) Alexandria dental journal (2015) 40;1-7

2. John Ingle, Leif K Bakland ; Endodontics, Fifth Edition; 2002:571-668.

3. Cobankara FK, Adanir N,Belli S,Pashley DH.A quantitative evaluation of apical leakage of four root canal sealer.International endodontic journal 2002;35(12):979-984.

4. Monticelli F,Sword J, Martin RL, Schuster GS et al. Sealing properties of two contemporary single-cone obturation system. International Endodontic Journal 2007;40(5):374-385.

5. Herbert Schilder: Filling root canals in three dimentions. Dental Clinics of North America; November 1967:723-744.

6. R. Prakash, V Gopikrishna, Kandaswamy D: Gutta percha-An untold story; Endodontology 2005;17(2):32-36.

7. Hedge V. and Arora S sealing ability of novel hydrophilic vs conventional hydrophobic obturation system; a bacterial leakage study J Conserve dent 2015; 18; 1:62-65.

8. Punia S K,Nadig P,Punia V. An in in vitro assessment of apical microleakage in root canal obturated with Guttaflow,resilion,thermafill and lateral condensation-A stereomicroscopic study.JConserv dent 2011;14;

9. Economides N, Gogos C, Kodonas K, Beltes C, Kolokouris I. An ex vivo comparison of the push-out bond strength of a new endodontic filling system (Smartseal) and various gutta percha filling techniques. Odontology 2012; 100: 187-191.

10. G. De-Deus, M. C. Branda o, R. A. S. Fidel \& S. R. Fidel The sealing ability of GuttaFlowTM in oval-shaped canals: an ex vivo study using a polymicrobial leakage model. Int Endod J. 2007 Oct;40(10):794-9. Epub 2007 Aug 22.

11. Endodontics in Clinical Practice. 2nd edn. F J Harty, (Pp 280; £10.) Wright PSG. 1982.

12. Nicholls E Endodontics. 3rd edition John Wright \& Sons Ltd, 1984:221-245.

13. Dalat D.M and Spanberg L.S.W. Comparison of apical leakage in root canals obturated with various guttapercha techniques using a dye vacuum tracing method. J Endod1994; 20: 315-319.

14. Franklin S Weine; Endodontic Therapy: six edition; chapter 7; 2010:266-313.

15. R. Prakash, V Gopikrishna, Kandaswamy D: Gutta-Percha- An untold story; Endodontology 2005; 17 (2): 32 36

16. Gu XH, Mao CY, Liang C, Wang HM et al. Does endodontic post space irrigation affect smear layer removal and bonding effectiveness;European Journal of Oral Sciences 2009; 117 (5);597-603

17. Wu H, Hayahi M, Okamura K, Koytchev EV et al. E ffects of light penetration and smear layer removal on adhesion of post cores to root canal dentin by self-etching adhesives.Dental Materials 2009; 25 (12); 1484-1492

18. Cecchin D, Affonso de Almeida JF, Gomes B and zaia AA et al. Effect of chlorhexidine and ethanol on the durability of the adhesion of the fiber post relined with resin composite to the root canal. Journal of endodontics 2011; 37 (5): 678-683

19. khedmat S, Aligoli M and Jafari M; Combined bacterial-fungal penetration after obturation with AH 26 and AH Plus root canal sealer.Journal of dentistry 2009;6(4): 187-192.

20. Nunes V H, Gariba R, Alfredo E and Sousa-Neto MD et al; Adhesion of epiphany and AH Plus sealer to human root dentin treated with different solution. Brazilian Dental Journal 2008; 19(1): 46-50.

21. Ken Koch, DMD; Dennis Brave, DDS; and Allen Ali Nasseh, DDS, MMSc;A review of bioceramic technology in endodontics. Roots. 2012;4:6-12.

22. Ersahan S, Aydin C. Dislocation resistance of iRoot SP, a calcium silicate-based sealer, from radicular dentine. J Endod. 2010;36:2000-2

23. Kossev D, Stefanov V. Ceramics-based sealers as new alternative to currently used endodontic sealers. Roots. 2009;1:42-8.

24. Afaf AL-Haddad and Zeti A. Che Ab Aziz Bioceramic-Based Root Canal Sealers: A Review.International Journal of Biomaterials Volume 2016 (2016), Article ID 9753210, 10 pages 
25. Shipper G, Orstavik D, Teixeira FB, Trope M. An evaluation of microbial leakage in roots filled with a thermoplastic synthetic polymer-based root canal filling material (Resilon). J Endod. 2004;30:342-7.

26. Wu MK, De Gee AJ, Wesselink PR, Moorer WR. Fluid transport and bacterial penetration along root canal fillings. Int Endod J. 1993 Jul;26(4):203-8.

27. Tagger M, Tamse A, Katz A, Tagger E. An improved method of three-dimensional study of apical leakage. Quintessence Int. 1983; 14:981-98.

28. Czonstkowsky M, Michanowicz A, Vazquez JA. Evaluation of an injection of thermoplasticized lowtemperature gutta-percha using radioactive isotopes. J Endod. 1985;11:71-4.

29. Matloff IR, Jensen JR, Singer L, Tabibi A. A comparison of methods used in root canal sealability studies. Oral Surg Oral Med Oral Pathol. 1982;53(2):203-8.

30. Kersten HW, Ten Cate JM, Exterkate RA, Moorer WR, Thoden van Velzen SK. A standardized leakage test with curved root canals in artificial dentine. Int Endod J. 1988;21:191-9.

31. Starkey DL, Anderson RW, Pashley DH. An evaluation of the effects of methylene blue dye $\mathrm{pH}$ on apical leakage. J Endod. 1993;19:435-9.

32. Taschieri S, Del Fabbro M, Francetti L, Testori T. Effect of rootend resection and root-end filling on apical leakage in the presence of core-carrier root canal obturation. Int Endod J. 2004;37:477482.

33. Venturi M, Breschi L. Evaluation of apical filling after warm vertical gutta-percha compaction using different procedures. J Endod. 2004;30:436-40.

34. Patil P, Vishnu P, Rathore S, Hotker C, Snehal S, Raghvendra K, Ingale P(2016)

35. A comparison of apical sealing ability between GuttaFlow and AH plus: An in vitro study.

36. Elayouti A, Achleithner C, Lost C, Weiger R; Homogeneity and adaptation of a new gutta-percha paste to root canal walls. J Endod. 2005 Sep;31(9):687-90. 